\title{
The Case for Stimulating a Planetary Protection Framework for Emerging Private Space Activities
}

\author{
George Profitiliotis
}

Unit of Environmental Science and Technology, School of Chemical Engineering, National Technical University of Athens, Athens, Greece https://doi.org/10.38126/ISPG160206

Corresponding Author: gprofitil@mail.ntua.gr

Keywords: planetary protection, forward contamination, backward contamination, space commercialization

Executive Summary: The emergence of private space activities is pushing the boundaries of the space industry with technological innovations that may soon enable the targeting of the novel market segments of space research and exploration, space resources utilization, and human access to space. Planetary protection is defined as a set of guidelines that aim to prevent the forward contamination of celestial bodies with biological material from Earth and the backward contamination of the terrestrial biosphere with extraterrestrial biological material. Significant questions are expected to be raised in the future with respect to potential forward and backward contamination issues of emerging private space activities. Unfortunately, the jurisdiction over and the enforcement of forward and backward contamination prevention measures to private space endeavors are currently facing policy and regulatory gaps and ambiguities. The key challenges with the current planetary protection policy landscape indicate that these contamination issues of private space activities can indeed have lasting negative impacts on social, economic, and environmental equity, sustainable development on Earth, and the sustainable exploration and development of other celestial bodies.

Drawing on its multidisciplinary expertise, the UN system is favorably positioned to play a key role in stimulating a novel planetary protection framework for emerging private space activities. Firstly, it can provide an international forum for the harmonization and agreement on such a framework. Secondly, it can create a financing mechanism to fund international research and development consortia of public and private organizations under a pre-competitive collaboration scheme for planetary protection technologies. Thirdly, it can establish a process of civic engagement to promote the meaningful participation of the civil society in the formulation of this framework. A prudent consideration of this matter may not only counteract the inequitable distribution of any unintended negative consequences, but may also facilitate economic development in a respectful, sustainable, and responsible manner.

I. Emerging private activities in research, exploration, and human access to space

The emergence of private space activities is pushing the boundaries of the space industry with technological innovations that may soon enable the targeting of the novel market segments of space research, science (González 2017), exploration, space resources utilization, and human access to space (Vernile 2018). Naturally, relevant business cases will first be pursued in suborbital space and in low earth orbit, via, for example, the operation of internal and external commercial service platforms aboard the International Space Station (KIWI 2019; Space Applications Services NV/SA 2019; ISS U.S. National Laboratory 2019; Airbus Defence and Space GmbH 2019). It can be expected that, in the future, relevant business cases might also involve 
venturing into even farther destinations such as the Moon and Mars.

Indeed, in 2019, NASA selected fourteen American companies that will be able to bid for delivery services to the lunar surface through Commercial Lunar Payload Services (CLPS) contracts, thus paving the way for commercial missions to the Moon (NASA 2020). Two of those companies have already stated that their proposed commercial cargo landers will be able to be used in sample return missions. These include the McCandless Lunar Lander by Lockheed Martin (Lockheed Martin Corporation 2018) and the MX-9 Frontier Class Explorer by Moon Express (Moon Express 2020a).

Moon Express is planning the first commercial lunar sample return mission as part of its 2020 Harvest Moon expedition. The collected lunar samples "will be the only privately owned Moon materials on Earth, and will be used to benefit science as well as commercial purposes" (Moon Express 2020b). Moreover, the Moon Express landers are currently marketed as both lunar and deep space exploration platforms, especially the MX-9 that can support lunar sample return missions (Moon Express 2020a).

These statements might indicate a long-term vision of a future value proposition of commercial sample return from Mars. The utilization of emerging commercial capabilities for Mars sample return within the framework of a governmental mission has also been investigated in a past feasibility study (Gonzales and Stoker 2016). Another work has proposed the business case of the commercial return of highly valuable Martian regolith and samples as one of the most straightforward candidates for a source of income for private Mars settlements during initial missions (Entrena Utrilla and Welch 2017).

In addition, the success of NASA's Mars Cube One (MarCO) CubeSats in the first interplanetary mission to use such devices has proven the concept of using miniaturized spacecraft for the unmanned exploration of Mars, thus opening up the path for potential future private CubeSat missions to Mars (NASA/JPL 2019). Lastly, the market segment of human access to space seems also to be a desired long-term goal of some private enterprises. These private endeavors include commercial manned suborbital flights (Blue Origin 2019; Virgin Galactic
2019), tourism in Low Earth Orbit (Axiom Space 2019; Forbes.com 2018), human-rated lunar landers (Blue Origin 2019), lunar passenger flights (SpaceX 2017), and human-rated bases around Mars (Lockheed Martin Corporation 2019) and on its surface (SpaceX 2017).

\section{Key challenges with the current planetary protection policy framework}

In the "Strategy on New Technologies", the United Nations Secretary-General has already recognized "private space travel" as an emerging and transformative possibility that holds promise for human welfare, yet may, at the same time, have unintended negative consequences (United Nations 2018). To facilitate the invigoration and the forthcoming growth of the new space economy being developed by private space actors, while minimizing the inequitable distribution of any unintended negative consequences, the interdisciplinary field of planetary protection has to keep up with technological advances and the business goals of the private sector.

Planetary protection is defined as a set of guidelines that aim to prevent the forward contamination of celestial bodies with biological material from Earth and the backward contamination of the terrestrial biosphere with extraterrestrial biological material (Frick et al. 2014). In Article IX of the United Nations Treaty on Principles Governing the Activities of States in the Exploration and Use of Outer Space, including the Moon and Other Celestial Bodies of 1967, also known as the Outer Space Treaty, the "harmful contamination" of the Moon and other celestial bodies and the "adverse changes in the environment of the Earth resulting from the introduction of extraterrestrial matter" are to be avoided (UNODA 2019). In accordance with this suggestion, the Committee on Space Research (COSPAR) maintains and promulgates its own planetary protection policy for the reference of space faring nations, to assist in the avoidance of organic-constituent and biological contamination of celestial bodies (forward contamination) and of the Earth (backward contamination) during space exploration (Kminek et al. 2017). However, both the recommendations of the Outer Space Treaty and COSPAR's planetary protection policy, rely on national laws and on the internal policies of public agencies for their enforcement.

As space entrepreneurs acquire and develop the resources and competencies for commercial access 
to space, significant questions are expected to arise in the future with respect to potential forward and backward contamination issues. For example, the recent crash of the privately funded Beresheet lander on the Moon, which resulted in the release of biological material on the lunar surface, already illustrates this (Shahar and Greenbaum 2020). Unfortunately, the jurisdiction over and the enforcement of forward and backward contamination prevention measures to private space endeavors are currently facing policy and regulatory gaps (Froehlich 2018) and ambiguities (Jakhu 2015).

In particular, up until now, the prevention of forward contamination of other celestial bodies during space exploration was overseen by public space agencies, which were the only organizations that maintained the capabilities necessary to conduct space missions. Private space companies were acting as subcontractors to public space agencies, working by their technical requirements as set out in state planetary protection guidelines. This method successfully controlled the quality and conformity of the deliverables of private subcontractors to public contractors. However, space entrepreneurs are now gradually acquiring and developing the resources and competencies to operate autonomously in the areas that were traditionally served by public space agencies.

Due to this change, a key challenge arises: the absence of a supranational mandatory framework that can enforce planetary protection requirements to private actors launching from every nation (Porras 2017). In addition, the minimization of the internal forward contamination prevention costs of future missions is expected to be a firm goal in the commercial space sector (Newman 2015). This goal will be even more crucial in the case of manned systems that require novel, and more expensive, contamination control methods (Conley and Rummel 2010). The combination of the aforementioned facts may give rise to unintended negative consequences of a global scope.

Joshua Lederberg (1960) realized early on that a failure to adhere to forward contamination mitigation requirements by one nation could have deleterious impacts to the present and future astrobiological research of every other nation. With respect to the prevention of the backward contamination of the Earth, any private missions that will involve a post re-entry phase on Earth for the recovery, transfer, reception, and distribution of samples and for the handling of returned people and equipment, may raise quarantine issues that have not been relevant since the Apollo era. It is likely that various public groups will vigorously scrutinize the environmental, health, and safety risks related to a potential backward contamination incident (Race 1995; Race 1998). It is also likely that they will review the contamination prevention measures for Earth-return missions. In case these are found inadequate, public groups may challenge the organization undertaking the mission in the courts (Race 1996) via the usage of numerous laws that may apply (Goh and Kazeminejad 2004). Litigation by concerned groups of the public will cause added direct and indirect costs to the private actors, for example, via the complex legal landscape, subsequent delays in the development activities, or missed launch windows (Race 1996; Race 1995). It may also lead to the formulation of a not so advantageous view towards commercial activities by the respective states (Hlimi 2014), as public opinion can influence the setting of public policies (Hofmann, Rettberg and Williamson 2010).

It has even been noted in the literature that the precautionary principle might be a potential strategy that decision makers or regulators could invoke to pre-emptively cope with space-related environmental issues (Langston 2018). Policies of this kind could shift the issue from the local to the global dimension. Judging from the current situation in the marine ship-breaking (Demaria 2016) and electronic waste handling industries (Sthiannopkao and Wong 2013), less wealthy countries might welcome the accumulation of such otherwise unwanted Earth-return facilities to attract investments and generate capital flow. However, in the event of a quarantine breach incident, those countries would be unable to respond in time, as their risk management methods and strategies are insufficient for hazardous materials (Zhang et al. 2017).

The aforementioned key challenges with the current planetary protection policy landscape indicate that both the forward and the backward contamination issues of private space activities can indeed have lasting negative impacts. These impacts refer to social, economic, and environmental equity, sustainable development on Earth, and the sustainable exploration and development of other celestial bodies. 


\section{Opportunities for a tangible path forward}

Although private space activities currently do not seem to pose a serious planetary protection threat, certain preparatory steps need to be taken in order to prudently inform the relevant policy-making procedures. This must be done before the emergence of an uncontrollable increase of commercial demands (Ehrenfreund, Race and Labdon 2013) and industrial developments (Hofmann, Rettberg and Williamson 2010). Drawing on its multidisciplinary expertise, the UN system is favorably positioned to play a key role in stimulating a novel planetary protection framework for emerging private space activities. As the enforcement of space law is a national matter, the UN system can only support the international harmonization of planetary protection regulations for private space activities, as they are being addressed in national space laws. The harmonization of national space laws in general is already being addressed in the UN system through the United Nations Committee on the Peaceful Uses of Outer Space and its Secretariat, the United Nations Office for Outer Space Affairs. However, more emphasis should be given to extended consultations centered on planetary protection regulations for private space activities. In these consultations, specialized UN agencies, such as the World Health Organization and the United Nations Educational, Scientific and Cultural Organization, could also provide informed feedback.

Besides providing an international forum for the harmonization and agreement on a novel international planetary protection framework for emerging private space activities, two other initiatives may be critical in addressing the key challenges previously described.

The first would be the creation of a financing mechanism to fund international consortia of public and private organizations aiming to research and develop technologies for the mitigation of forward and backward contamination, under a precompetitive collaboration scheme (Fernandez et al. 2016). This financing mechanism could be centered on the gradual development of a flagship project that might take the form of an international planetary protection analogue program and its respective testbed facility (Conley and Rummel 2008).

The second initiative would be the establishment of a process of civic engagement to promote the meaningful participation of the civil society in the formulation of this novel planetary protection framework for emerging private space activities. This engagement could be fostered through participatory scenario planning workshops (Olabisi et al. 2018) that could generate considered guidance and insights, with respect to community preferences and concerns regarding emerging private space activities.

In conclusion, a prudent consideration of the key challenges with the current planetary protection landscape, in light of the emerging private space activities, may not only preemptively counteract the inequitable distribution of any unintended negative consequences. It may also facilitate economic development in a respectful, sustainable, and responsible manner.

\section{References}

Airbus Defence and Space GmbH. 2019.

"Bartolomeo". Accessed August 2, 2019. https://www.airbus.com/space/spaceinfrastructures/bartolomeo.html

Blue Origin. 2019. "Lunar Transport: Blue Moon." Accessed August 2, 2019. https://www.blueorigin.com/blue-moon

Blue Origin. 2019. "Suborbital Spaceflight: New Shepard." Accessed August 2, 2019. https://www.blueorigin.com/new-shepard/

Conley, Catharine A and John D Rummel. 2010. "Planetary protection for human exploration of Mars." Acta Astronautica 66, 792-797. https://doi.org/10.1016/j.actaastro.2009.08. $\underline{015}$
Conley, Catharine A. and John D. Rummel. 2008.

"Planetary protection for humans in space:

Mars and the Moon." Acta Astronautica 63:

1025-1030.

https://doi.org/10.1016/j.actaastro.2008.03. $\underline{012}$

Demaria, Federico.2016. "Can the Poor Resist Capital? Conflicts over 'Accumulation by Contamination' at the Ship Breaking Yard of Alang (India) - How Struggles for Environmental Justice Contribute to the Environmental Sustainability of the Economy." In Nature, Economy and Society Understanding the Linkages, edited by Nilanjan Ghosh, Pranab Mukhopadhyay, Amita Shah and Manoj Panda, 273-304. New Delhi, India: Springer (India) Pvt. Ltd. https://doi.org/10.1007/978-81-322-2404$\underline{414}$ 
Ehrenfreund, P, M Race and D Labdon. 2013.

"Responsible space exploration and use: Balancing stakeholder interests." New Space 1, no.2: 60-72. https://doi.org/10.1089/space.2013.0007

Entrena Utrilla, C. M. and C. Welch. 2017. "Development Roadmap and Business Case for a Private Mars Settlement." New Space 5, no. 3: 170-185. https://doi.org/10.1089/space.2017.0024

Fernandez, FF, E Vasconcellos, LF Guedes, R Carlana, and V Da Matta. 2016. "Long-Term R\&DBased Consortia: Paths to Integrate Basic Research with Company Strategy." Orlando, Florida: 25th International Association for Management of Technology Conference, 15-19 May 2016, 973-992.

Forbes.com. 2018. "Mankind's First Space Hotel Is Coming In 2021 - Probably." Accessed August 2, 2019.

https://www.forbes.com/sites/duncanmadd en/2018/03/09/mankinds-first-space-hotelis-coming-in-2021-probably/

Frick, Andreas, Rakesh Mogul, Pericles Stabekis, Catharine A. Conley, and Pascale Ehrenfreund. 2014. "Overview of current capabilities and research and technology developments for planetary protection." Advances in Space Research 54, no.2: 221240.

https://doi.org/10.1016/i.asr.2014.02.016

Froehlich, Annette. 2018. "Analysis of the Views of Both Established and Emerging Space Nations Regarding the Topic and Also Regarding the New US CSLCA of 2015." In Space Resource Utilization: A View from an Emerging Space Faring Nation, edited by Annette Froehlich, 41-80. Cham, Switzerland: Springer International Publishing AG. https://doi.org/10.1007/978-3-319-66969$\underline{4} 5$

Goh, G. M. and B. Kazeminejad. 2004."Mars through the looking glass: an interdisciplinary analysis of forward and backward contamination." Space Policy 20, no.3: 217225.

https://doi.org/10.1016/j.spacepol.2004.06. $\underline{008}$

Gonzales, Andrew A and Carol R Stoker. 2016."An efficient approach for Mars Sample Return using emerging commercial capabilities." Acta Astronautica 123: 16-25. https://doi.org/10.1016/j.actaastro.2016.02. $\underline{013}$

González, Augusto. 2017. A Snapshot of Commercial Space: an EU Fellowship Report. Boulder: Center for Science and Technology Policy Research.
Hlimi, Tina. 2014."The Next Frontier: An Overview of the Legal and Environmental Implications of Near Earth Asteroid Mining. " Annals of Air and Space Law: 409-453.

Hofmann, M, P Rettberg and W Williamson. 2010. Protecting the Environment of Celestial Bodies: The Need for Policy and Guidelines. Paris, France: International Academy of Astronautics (IAA).

ISS U.S. National Laboratory.2019.“Science in space to benefit life on Earth.". Accessed August 2, 2019. https://www.issnationallab.org/

Jakhu, R.S. 2015. "Regulatory Aspects Associated with Response to Man-Made Cosmic Hazards." In Handbook of Cosmic Hazards and Planetary Defense, edited by Joseph N. Pelton and Firooz Allahdadi, 1069-1084. Cham, Switzerland: Springer International Publishing Switzerland. https://doi.org/10.1007/978-3-319-039527664

KIWI. 2019. "KIWI: your ticket to microgravity." Accessed August 2, 2019. http://www.kiwi-microgravity.com/

Kminek, G, C Conley, V Hipkin and H Yano. 2017. COSPAR's Planetary Protection Policy. Paris: COSPAR.

Langston, Sara M. 2018."Reimagining Icarus: Ethics, Law and Policy Considerations for Commercial Human Spaceflight." In Into Space: A Journey of How Humans Adapt and Live in Microgravity, edited by Thais Russomano, 1-16. London, UK: IntechOpen Limited. https://doi.org/10.5772/intechopen.74716 Lederberg, Joshua. 1960."Exobiology: Approaches to Life beyond the Earth." Science: 393-400.

Lockheed Martin Corporation. 2018. "Lockheed Martin Selected for NASA's Commercial Lunar Lander Payload Services Contract. Accessed August 2, 2019. https://news.lockheedmartin.com/2018-1129-Lockheed-Martin-Selected-for-NASAsCommercial-Lunar-Lander-Payload-ServicesContract

Lockheed Martin Corporation. 2019. "Mars Base Camp." Accessed August 2, 2019. https://www.lockheedmartin.com/enus/products/mars-base-camp.html

Moon Express. 2020a. "Scalable Robotic Spacecraft." Accessed January 25, 2020. http://moonexpress.com/\# explorers

Moon Express. 2020b. "Three Maiden Expeditions." Accessed January 25, 2020. http://moonexpress.com/\#expeditions 
NASA. 2020. "First Commercial Moon Delivery Assignments to Advance Artemis." Accessed January 26, 2020.

https://www.nasa.gov/feature/firstcommercial-moon-delivery-assignments-toadvance-artemis

NASA/JPL. 2019. "Beyond Mars, the Mini MarCO Spacecraft Fall Silent." Accessed August 2, 2019.

https://www.jpl.nasa.gov/news/news.php?f eature $=7327$

Newman, Christopher J. 2015. "The new space ethics: COSPAR, Planetary Protection and beyond."

Accessed August 2, 2019.

https://room.eu.com/article/The new space ethics COSPAR Planetary Protection and $b$ eyond

Olabisi, Laura Schmitt, Saweda Liverpool-Tasie, Louie Rivers III, Arika Ligmann-Zielinska, Jing Du, Riva Denny, Sandra Marquart-Pyatt, et al. 2018. "Using participatory modeling processes to identify sources of climate risk in West Africa." Environment Systems and Decisions 38: 23-32. https://doi.org/10.1007/s10669-017-9653$\underline{6}$

Porras, Daniel A. 2017. "Astro-propriation: Investment Protections for and from Space Mining Operations." In Space India 2.0: Commerce, Policy, Security and Governance Perspectives, edited by Rajeswari Pillai Rajagopalan and Narayan Prasad, 311-334. New Delhi, India: Observer Research Foundation.

Race, M. S. 1998. "Mars sample return and planetary protection in a public context." Advances in Space Research 22, no.3: 391-399. https://doi.org/10.1016/S02731177(98)00036-2

Race, M.S. 1995. "Societal issues as Mars mission impediments: planetary protection and contamination concerns." Advances in Space Research 15, no. 3: 285-292.

https://doi.org/10.1016/S02731177(99)80099-4

Race, M.S. 1996. "Planetary protection, legal ambiguity and the decision making process for Mars sample return." Advances in Space Research 18, no.1-2: 345-350. https://doi.org/10.1016/02731177(95)00826-Z
Shahar, K. and D Greenbaum. 2020."Lessons in space regulations from the lunar tardigrades of the Beresheet hard landing." Nature Astronomy 4: 208-209. https://doi.org/10.1038/s41550-020-1034$\underline{2}$

Space Applications Services NV/SA. 2019. "Ice Cubes." Accessed August 2, 2019. http://www.icecubesservice.com/\#whats-is

SpaceX. 2017. "Missions to Mars." Accessed August 2, 2019. https://www.spacex.com/mars

Sthiannopkao, Suthipong and Ming Hung Wong.2013. "Handling e-waste in developed and developing countries: Initiatives, practices, and consequences." Science of The Total Environment 463-464: 1147-1153. https://doi.org/10.1016/j.scitotenv.2012.06. $\underline{088}$

United Nations. 2018. "Secretary-General's Strategy on New Technologies." Accessed September 6, 2019. https://www.un.org/en/newtechnologies/

UNODA. 2019. "Treaty on Principles Governing the Activities of States in the Exploration and Use of Outer Space, including the Moon and Other Celestial Bodies." Accessed September 1, 2019).

http://disarmament.un.org/treaties/t/outer space

Vernile, Alessandra. 2018. The Rise of Private Actors in the Space Sector. Vienna, Austria: European Space Policy Institute. https://doi.org/10.1007/978-3-319-738024

Virgin Galactic. 2019. "Mission: What We Do." (accessed August 2, 2019). https://www.virgingalactic.com/mission/

Zhang, H., Huabo Duan, Jian Zuo, Ming Wei Song, Yukui Zhang, Bo Yang, and Yongning Niu. 2017. "Characterization of post-disaster environmental management for Hazardous Materials Incidents: Lessons learnt from the Tianjin warehouse explosion, China." Journal of Environmental Management 199: 21-30. https://doi.org/10.1016/j.jenvman.2017.05. $\underline{021}$

George Profitiliotis is currently employed as a Foresight Expert at the UNESCO Chair on Futures Research and the Foresight \& Tools Unit of PRAXI Network, a unit of the Foundation for Research \& Technology Hellas (FORTH) in Greece. In parallel, he is also a final-year PhD candidate at the National Technical University of Athens (NTUA), researching the application of an environmental economics \& policy approach to the Planetary Protection issues that may arise in the future, especially in light of upcoming private space activities on Mars. He graduated as an Electrical \& Computer Engineer from the NTUA and 
he holds an interdisciplinary MSc in "Environment and Development" offered by the same university. He is also a graduate of the interdisciplinary educational program "Tech MiniMBA: Leading Strategic Innovation" offered by the Athens Information Technology institute and he has conducted voluntary internships at the Hellenic Space Technologies and Applications Cluster (si-Cluster) of the Corallia Clusters Initiative and at the Hellenic National Bioethics Commission, the latter on the research topic of the "Bioethics of Bioastronautics". 